ScIDice

\section{The Importance of Methods Imaging in the Diagnosis of Displacement to Mandibular Molar Root Fragment: Case Report}

ISSN: $2377-8075$

Case Report

Munerato $\mathrm{MS}^{1}$, Costa $\mathrm{BE}^{2 *}$, Junior $\mathrm{PDR}^{1}$, Gulinelli $\mathrm{JL}^{1}$, Cardoso $\mathrm{CL}^{1}$

${ }^{1}$ Department of Oral and Maxillofacial Surgery, University of the Sacred Heart, Bauru, São Paulo.

${ }^{2}$ University of Sao Paulo (HRAC/USP), Bauru, São Paulo.

\title{
Abstract
}

The aim of this study discusses the causes, prevention measures, diagnostic means for locating, treatment the displacement of the lower third molar root to the submandibular space during extraction. This article describes a clinical case showing the displacement of a lower third molar root to the submandibular space. The breaking of surgical planning during the surgical act or in the post-operative period is an unexpected situation that can happen, making normal tissue repair more difficult or delayed. Among third molar extraction accident reports, tooth or root displacement to neighboring anatomical areas is of low incidence. However, this fact may entail in complications such as infections, trismus, and paresthesia, increasing procedure morbidity. The displacement of lower third molar teeth or roots to adjacent anatomic spaces is a little-described accident in the literature. The fine lingual cortical associated with an inadequate surgical approach and the excessive use of force during extraction are the main causes, developing local disorders such as edema, trismus, difficulty in swallowing, abscesses and even paresthesia due to nerve bundle compression. The exact location through computerized images facilitates the surgical planning of the exeresis, which should preferably be performed by an experienced professional in the field.

Keywords: Third Molars; Retained Teeth; Complications; Submandibular Space; Methods Imaging.

\section{Introduction}

The lower third molar is one of the dental elements that give rise to most disorders caused by its irruption, making its extraction one of the most performed procedures for therapeutic or prophylactic reasons [1]. The surgical should be based on a correct diagnosis and adequate planning thus leading to successful extraction. The majority of accidents related to the procedure are due to incorrect surgical approach, distorted or insufficient radiographs, inadequate surgical material and instruments, untimely movement, lack of ability by the surgeon, and little anatomical knowledge of the operated on area.

However, the elaboration of an adequate surgical plan does not always ensure the absence of trans or post-operative problems. With regard to lower third molar extraction, these accidents/complications when ranked according to their frequency, would be infections leading to eventual abscesses, alveolitis [2, 3], paresthesia of the lingual or lower alveolar nerve $[4,5]$ hemorrhages $[2$,
6], mandible fractures [7] and the displacement of teeth or dental fragments to neighboring anatomical regions. This displacement can occur toward the lateral or medial region of the mandible, thus penetrating the pterigomandibular, submandibular, or sublingual space, among others. Research on this topic presents few reports of lower third molar lodging in neighboring regions.

However, when this does occur, it is common to solicit the intervention of maxillofacial surgery specialists for evaluation and treatment, since they end up causing disorders in the tissue repair process. The objective of this article is to present a case of root displacement to the submandibular space and to discuss the causes, the problems created by the displacement, and the pertinent solutions, as well as to propose some prevention measures.

\section{Case Report}

A 25 year old, leucoderma, male patient came to the Bucco-Maxillofacial Traumatology and Surgery clinic at the Universidade do

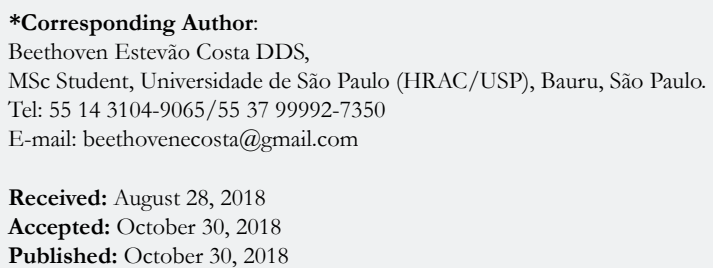

Copyright: Costa $\mathbf{B E}^{\circ}$ 2018. This is an open-access article distributed under the terms of the Creative Commons Attribution License, which permits unrestricted use, distribution and reproduction in any medium, provided the original author and source are credited. 
Sagrado Coração, forwarded by a dentist 50 days after the extraction of the lower right third molar (48), which was impacted in a mesioangular position, with the suspicion of the presence of a radicle fragment left in the alveolus after an orthopantomographic radiograph (Figure 1).

The surgery was reportedly long, and there were limited buccal opening, edema and localized hematomas, which were disappearing with time and the prescribed medication. However, the patient was complaining about an uncomfortable and persistent feeling of anesthesia in the anterior two-thirds of his tongue. The clinical examination revealed paresthesia and dysesthesia of the right side of the lingual nerve and a good range of buccal opening. The physical exam through palpation of the buccal floor region near the mandibular fovea revealed hard tissue with painful symptomatology. Periapical radiographs and Donovan modified radiograph takes, observed in Figure 2, revealed a root fragment in the medial portion of the mandible, lodged in the soft tissue of the lingual region.

After planning, surgical removal of the radicular remains was decided upon. For the exact location of the fragment, a computerized tomography in axial, coronal and three-dimensional mounting was requested beforehand (Figure 3). Through these exams, it was possible to ascertain the presence of the root near the submandibular space.

Exeresis of the radicular remains was conducted under local anesthesia using the infiltration of mepivacaine at $2 \%$ and adrenaline at 1:100,000, 60 days after the first intervention. Using a number 15 scalpel blade, a $1.5 \mathrm{~cm}$ incision was made in the floor of the mouth near the fragment. The musculature was divulsed using a blunt tip scissors until exposing the root, which was then removed using a hemostatic pincer (Figure 4). The surgical wound was then irrigated with physiological serum at $0.9 \%$, sutured with 910 polyglactin thread (Vicryl 4-0). The patient has prescribed an analgesic and an antibiotic.

The sutures were removed after 7 days, and periodic controls were scheduled. After approximately 30 days, the patient showed improvement in the paresthesia of the lingual nerve, and at present is under observation without complaint.

\section{Discussion}

According to [1], some of the anatomic areas adjacent to the lower third molars, also known as facial spaces, are sometimes invaded by dental elements or root fragments due to inadequate diagnosis and incorrect planning or exodontia conduct. The literature describes some cases, such as $[3,10]$, who report the removal of a lower third molar that had displaced to the cervical region, in the subcutaneous tissue, in contact with the sternocleidomastoid muscular fascia, using an extra-buccal approach 16 months after the accident. However, since the lingual cortical is normally thin, dental displacement ends up being more frequent in this area [9]. Described the removal of the radicular remains of tooth 48 that had displaced to the pterygomandibular space 9 days after exodontia. This space is limited laterally by the medial surface of the mandibular branch, medially by the medial pterygoid muscle and on top by the lateral pterygoid muscle. The surgical approach was intraoral, to remove the lingual alveolar wall, divulsion of the medial pterygoid muscle and removal of the fragment using a curved hemostatic pincer. Grandini at al., 1992 [11], similar to the clinical case described in this article, described two situations involving

Figure 1. Orthopantomographic radiograph showing an image compatible with radicular remains in the alveolus of tooth 48.

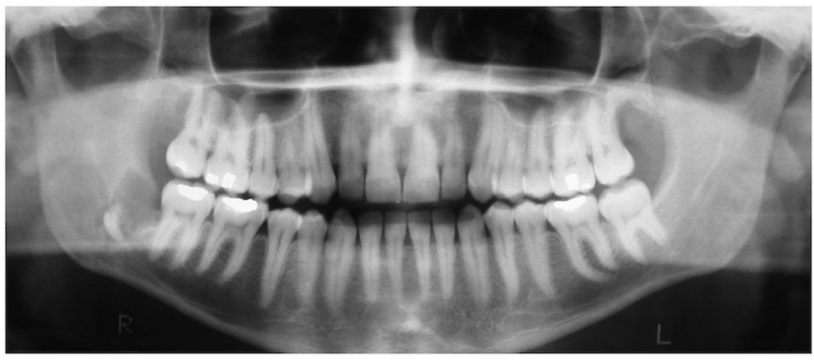

Figure 2. Donovan modified periapical radiograph take showing radicular fragment of tooth 48 displaced to the lingual region.

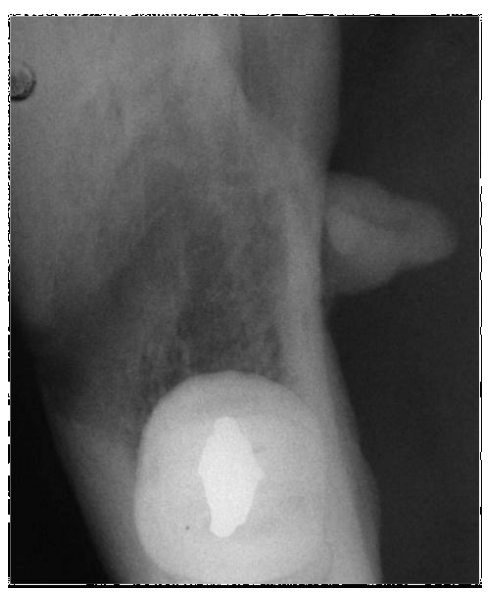


Figure 3. Computerized tomograph in coronal cuts showing the lingual cortical fenestration (A-B), the three-dimensional reconstruction revealing the location of root in the submandibular space (C-D).

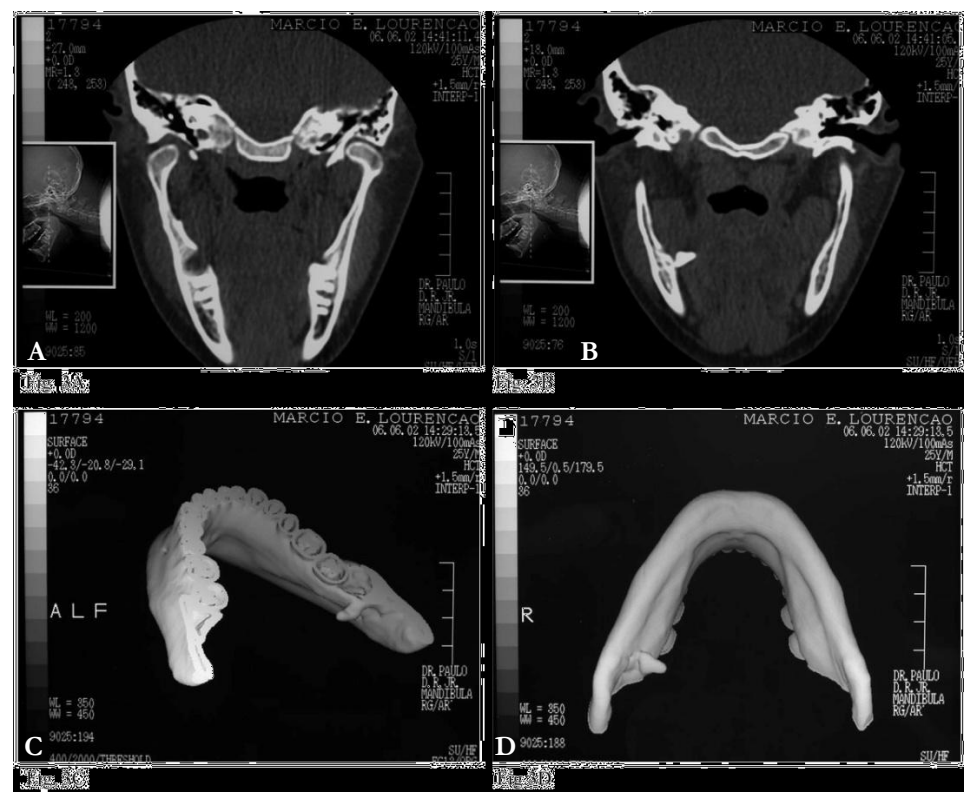

Figure 4. Trans operatory view the root fragment.

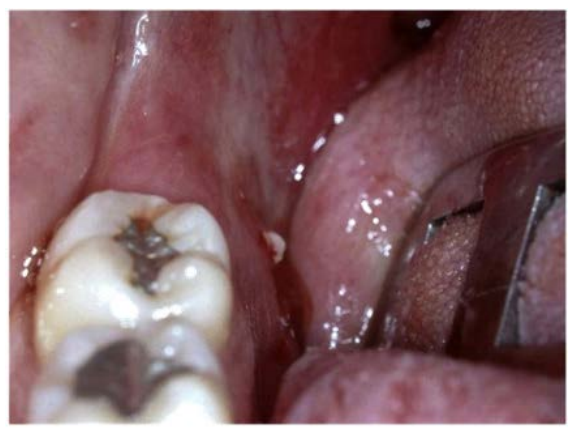

dental displacement to the submandibular space region. Considered a primary facial space, its upper limit is the mylohyoideus line, where the mylohyoideus muscle is inserted, laterally there is the mandible's medial facies, medially there is the internal portion of the mylohyoideus muscle, and underneath is the insertion of this muscle in the hyoideus bone [10].

The mandible's posterior teeth are frequently found with their apices located below the mylohyoideus line, maintaining intimate proximity to the submandibular space. The bony tissue that separates them may even be thinner along the third molars, in the submandibular fossa, where the submandibular gland is lodged. Tumuluri \& Punnia-Moorthy 2002 [9], have described research showing the presence of rare fenestrations in the lingual wall near the third molar apices, when the crown of this retained tooth finds itself turned more toward the vestibular side. The application of excessive force with extractors, especially in the wedge movement can cause the fracturing of the fine lingual bone layer and displacement of the root, or even the entire tooth to the above-mentioned anatomic spaces.

Basic surgical principles, such as the incision and the mucoperiosteal detachment of the flap, should allow for a surgical field providing good visibility for the surgeon. The adequate elimination of bone and radicular retentions, through osteotomies and odontotomies, allows for the extraction of retained teeth to be done with less force reducing the risk of accidents through the application of excessive and poorly directed force. Supporting the index finger over the lingual bone surface during exodontia maneuvers may help prevent dental displacement to adjacent anatomic spaces.

Conventional periapical radiographs and orthopantomographs do not permit the exact location of foreign bodies because they show images on a single plane [12]. Radiographs in occlusal takes, such as the total occlusal of the mandible or the Donovan modified technique, can reveal the location in terms of depth as long as the fragment is near the medial wall of the mandibular bone, as was possible to ascertain in the clinical case discussed herein. Computerized tomography in coronal as well as axial cuts, and the respective reconstruction in three dimensions show clear images of the displaced element in its correct position, as well as the fenestration point of the mandible [13].

The displacement of teeth or roots to neighboring spaces causes some disorders in tissue repair. Most of the patients complain of pain, difficulty in swallowing and limited buccal opening due to the edema and the inflammatory reaction in the days after the accident. These signals and symptoms tend to decrease in intensity as time goes by, following the fibrosis process around the foreign body. However, when they are persistent, or when they evolve to post-operative infection, localized abscesses and/or paresthesia 
due to nerve compression, it is common to look for help from specialists for surgical removal. Although the ideal scenario would be immediate removal, at the moment of the accident, a complicated exodontia, of long duration, leaves the patient exhausted, anxious, and not very cooperative, thus opting for intervention at a later date under more adequate local and systemic, and even psychological conditions [21]. Specifically concerning lower third molars, the consulted literature reveals a great variation for the period of the second surgery, from approximately one week $[8,9]$ up to three years [11]. In the clinical case described in this article, extraction of the fragment was performed after 60 days. The experienced professional's good sense, the intensity of the alterations the displaced element is causing and the patient's positive attitude should be determining factors to define when the intervention should be scheduled, in most cases under local anesthesia and using the intra-buccal approach. The risk of greater local damage, such as displacement to even deeper planes or lesions to nerve bundles, suggest that the surgery should be done by a specialized professional.

\section{Conclusion}

The displacement of lower third molar teeth or roots to adjacent anatomic spaces is a little-described accident in the literature. The fine lingual cortical associated with an inadequate surgical approach and the excessive use of force during extraction are the main causes, developing local disorders such as edema, trismus, difficulty in swallowing, abscesses and even paresthesia due to nerve bundle compression. The exact location through computerized images facilitates the surgical planning of the exeresis, which should preferably be performed by an experienced professional in the field.

\section{References}

[1]. Varvara G, Murmura G, Cardelli P, De DA, Caputi S, Sinjari B, et al. Mandibular third molar displaced in the sublingual space: clinical management and medicolegal considerations. J Biol Regul Homeost Agents. 2016 AprJun;30(2):609-13. PubMed PMID: 27358157.

[2]. de Boer MP, Raghoebar GM, Stegenga B, Schoen PJ, Boering G. Complications after mandibular third molar extraction. Quintessence Int. 1995 Nov;26(11):779-84. PubMed PMID: 8628837.

[3]. Gay-Escoda C, Berini-Aytes L, Piñera-Penalva M. Accidental displacement of a lower third molar: Report of a case in the lateral cervical position. Oral Surg Oral Med Oral Pathol. 1993 Aug;76(2):159-60. PubMed PMID: 8361724.

[4]. Blackburn CW, Bramley PA. Lingual nerve damage associated with the removal of lower third molars. Br Dent J. 1989 Aug 5;167(3):103-7. PubMed
PMID: 2765316.

[5]. Smith AC, Barry SE, Chiong AY, Hadzakis D, Kha SL, Mok SC, et al. Inferior alveolar nerve demage following removal of mandibular third molar teeth. A prospective study using panoramic radiography. Aust Dent J. 1997 Jun;42(3):149-52. PubMed PMID: 9241922.

[6]. Goldberg MH, Nemarich AN, Marco WP. Complications after mandibular third molar surgery: a statistical analysis of 500 consecutive procedures in private practice. J Am Dent Assoc. 1985 Aug;111(2):277-9. PubMed PMID: 3862695.

[7]. Krimmel M, Reinert S. Mandibular fracture after third molar removal. J Oral Maxillofac Surg. 2000 Oct;58(10):1110-2. PubMed PMID: 11021704

[8]. Hutchinson D. An unusual case of lingual displacement of a mandibular third molar root apex. Oral Surg Oral Med Oral Pathol. 1975 Jun;39(6):85861. PubMed PMID: 1055971.

[9]. Tumuluri V, Punnia-Moorthy A. Displacement of a mandibular third molar root fragment into the pterygomandibular space. Aust Dent J. 2002 Mar;47(1):68-71. PubMed PMID: 12035962.

[10]. Aznar-Arasa L, Figueiredo R, Gay-Escoda C. Iatrogenic displacement of lower third molar roots into the sublingual space: report of 6 cases. J Oral Maxillofac Surg. 2012 Feb;70(2):e107-15. doi: 10.1016/j.joms.2011.09.039. PubMed PMID: 22260911

[11]. Grandini SA, Barros VM, Salata LA, Rosa AL, Soares UN. Complications in exodontias--Accidental dislodgment to adjacent anatomical areas. Braz Dent J. 1993;3(2):103-12. PubMed PMID: 8241759.

[12]. Manor Y, Abir R, Manor A, Kaffe I. Are different imaging methods affecting the treatment decision of extractions of mandibular third molars?. Dentomaxillofac Radiol. 2016 Dec 18:20160233. PubMed PMID: 27990846.

[13]. Matzen LH, Wenzel A. Efficacy of CBCT for assessment of impacted mandibular third molars: a review-based on a hierarchical model of evidence. Dentomaxillofac Radiol. 2015;44(1):20140189. doi: 10.1259/ dmfr.20140189. PubMed PMID: 25135317.

[14]. De AB, Guerra F, Giordano G, Salucci S, Solidani M. Surgical removal of a left lower third molar root after iatrogenic displacement in soft tissue. Case report. Minerva Stomatol. 2005 Jun;54(6):389-93. PubMed PMID: 16175168.

[15]. Ertas Ü, Yaruz MS, Tozoğlu S. Accidental third molar displacement into the lateral pharyngeal space. J Oral Maxillofac Surg. 2002 Oct;60(10):1217. PubMed PMID: 12378505.

[16]. Kamburoglu K, Kursun S, Oztas B. Submandibular displacement of a mandibular third molar root during extraction: a case report. Cases J. 2010 Jan 6;3:8. doi: 10.1186/1757-1626-3-8. PubMed PMID: 20148142

[17]. Özalp B, Kuvat SV, Emekli U. Conservative treatment of displacement mandibular third molar. J Craniofac Surg. 2010 Jul;21(4):1314-5. doi: 10.1097/ SCS.0b013e3181e1b2cf. PubMed PMID: 20647854.

[18]. Nusrath MA, Banks RJ. Unrecognised displacement of mandibular molar root into the submandibular space. Br Dent J. 2010 Sep 25;209(6):279-80. doi: 10.1038/sj.bdj.2010.816. PubMed PMID: 20871549.

[19]. Huang IY, Wu CW, Worthington P. The displaced lower third molar: a literature review and suggestions for management. J Oral Maxillofac Surg. 2007 Jun;65(6):1186-90. PubMed PMID: 17517304.

[20]. Yeh CJ. A simple retrieval technique for accidentally displaced mandibular third molars. J Oral Maxillofac Surg. 2002 Jul;60(7):836-7. PubMed PMID: 12089704.

[21]. Engelke W, Fuentes R, Beltrán V. Endoscopically assisted removal of a lingually displaced third molar adjacent to the inferior alveolar nerve. J Craniofac Surg. 2013 Nov;24(6):2171-4. doi: 10.1097/SCS.0b013e3182a2d834. PubMed PMID: 24220432. 